\title{
Grid generation research for intake-exhaust closing internal combustion engine using KIVA software
}

\author{
Zhao Tianpen $^{\mathrm{a}}$ \\ Beijing Research Centre of Sustainable Energy and Building \\ Beijing University of Civil Engineering and Architecture \\ Beijing 100044, China \\ a13811913654@163.com
}

\author{
Liu Yongfeng ${ }^{\mathrm{b} *}$, Shi Yan $^{\mathrm{c}}$ \\ Beijing Research Centre of Sustainable Energy and Building \\ Beijing University of Civil Engineering and Architecture \\ Beijing 100044, China \\ bliuyongfeng@bucea.edu.cn, csyst1988@163.com
}

\begin{abstract}
In order to simulate the combustion process of the internal combustion engine, a new grid generation was carried. This paper developed the KIVA-3V software to establish a gasoline engine combustion chamber model. Firstly, the schematic of grid generation and block of combustion zone is given out. The data file (IPREP) and other files are built up, and the grid data of gasoline engine combustion chamber is obtained. Secondly, the output files are obtained by running the KIVA-3V. Finally, the new three dimensional grids of the intake-exhaust closing internal combustion engine are obtained. It gives a new way to build up simulation grid for internal engine.
\end{abstract}

Keywords-KIVA3V; grid generation; internal combustion engine

\section{INTRODUCTION}

The pollution of the environment and the decrease of the energy have been the two serious problems in the word. It has become a highlight to researching the operation process especially combustion process for internal combustion engine. The method of numerical simulation can effectively forecast the complete performance of internal combustion engine and partly replace some engine experiment, and carry on various parameter researches in different operational modes without the time and space limit, guide the designs of engines with the new combustion system, optimize the performance of original engines. It can also forecast the power and exhaust emissions of the engine fired with various fuels. Therefore the method of numerical simulation has very powerful vitality and many advantages. The KIVA series program developed by Alamos National Laboratory in the United States is the most representative.

In 1985, the Los Alamos National Laboratory launched three-dimensional program KIVA for the simulation of chemical reaction in internal combustion engine. In 1989, A. Amsden Anthony developed the KIVA-2 program on the basis of KIVA. The calculation of efficiency and accuracy of the program has made great improvement. KIVA-2's formula and mathematical calculation process are universal, which can be used for laminar or turbulent, subsonic or supersonic flow, single phase flow or diffusion two-phase flow. In 1993, the Los Alamos National Laboratory developed KIVA-3 program based on the KIVA-2 program. The program uses a sub block structure, which can divide complex geometry into a number of simple blocks. Therefore, the program can calculate very complex geometries. It can not only save the storage space, but also improves the calculation speed. In 1997, KIVA-3V which is KIVA-3's improved version was complete. KIVA-3V increased oil film flow model, turbulent combustion model and soot model.

The development of simulation technology in China is relatively late. Two dimensional simulation is first applied. The most representative is Professor Wang Rongsheng and Professor Xie Maozhao of Dalian University of Technology. They finished the research of laminar flow in 1985. In recent years, the development of 3D simulation technology of internal combustion engine is very fast. Tongji University and Jiangsu University developed EngineCFD-11. University Of Science And Technology Of China developed IPIC-CFD. Beijing Institute of Technology developed RES3D-11. These simulation programs promote the development of engine research to a higher level.

KIVA program has been used more and more widely. As the mathematical model of KIVA program gradually becoming perfect, it can be used to simulate the combustion and emissions of an internal combustion engine. At present, the series of KIVA program has entered a golden stage of development. In the world, many universities, research institutions and major automobile companies are involved in the corresponding research. It is not only a tool for understanding the generation of combustion and harmful emissions, but also for the design of a new engine, which plays an important role in the automotive industry.

\section{PROCESS}

Since KIVA-3V is written in FORTRAN language, it is not like other simulation software which have visual interface, so it is necessary to explain the source code of KIVA-3V. The KIVA-3V program can be divided into three interrelated parts. (i)K3perp, the pre-processor, is using for generating computational grids. The shape of the combustion zone is generally divided into separate blocks such as top clearance, combustion chamber, inlet manifold and so on. The parameters of the shape of the combustion area should be entered into the iprep file which is a specific format file of KIVA-3V. Get Otape11 file after running the former processor K3perp. This file is mainly used to determine whether the 
input parameters meet the requirements. If yes, the program will generate otape17 file. (ii)Kiva3v, flow solver, generally need to enter two parameters which are itape17 file and itape5.dat file. Itape5.dat file is mainly used to define the ignition advance angle, fuel injection quantity, injection time, swirl ratio, rotating speed and so on. After running kiva3v, it will generate otape8, otape9, otape12 and other parameters file. (iii)K3post, post-processor, is using for generating the final file. As KIVA-3V is not an interface operation software, the program of post-processing need to use other software such as TECPLOT, Origin pro and so on. Fig.1 is the schematic of grid generation.

Firstly, write the cylinder bore, stroke, compression ratio, squish and other parameters to the iprep file. Secondly, run the K3PREP to generate the internal combustion engine's computational simulation grid model and get the otape17 file and the otape 11 file. And rename the generated grid data file otape17 as itape17 which is used as the input file to the KIVA$3 \mathrm{~V}$. At the same time, the swirl ratio, the ignition start time, the ignition duration, the top temperature of the cylinder, the piston surface temperature, the fuel injection quantity and the fuel injection mode are written in itape 5 which is the input file of KIVA-3V. Thirdly, run KIVA-3V to generate the otape9 file, the otape 8 file, the otape 12 file and other files. And rename otape9 file as itape9 file which is used as the input file of K3POST. Finally, run the postprocessor, K3POST, to get the combustion chamber mesh data file.

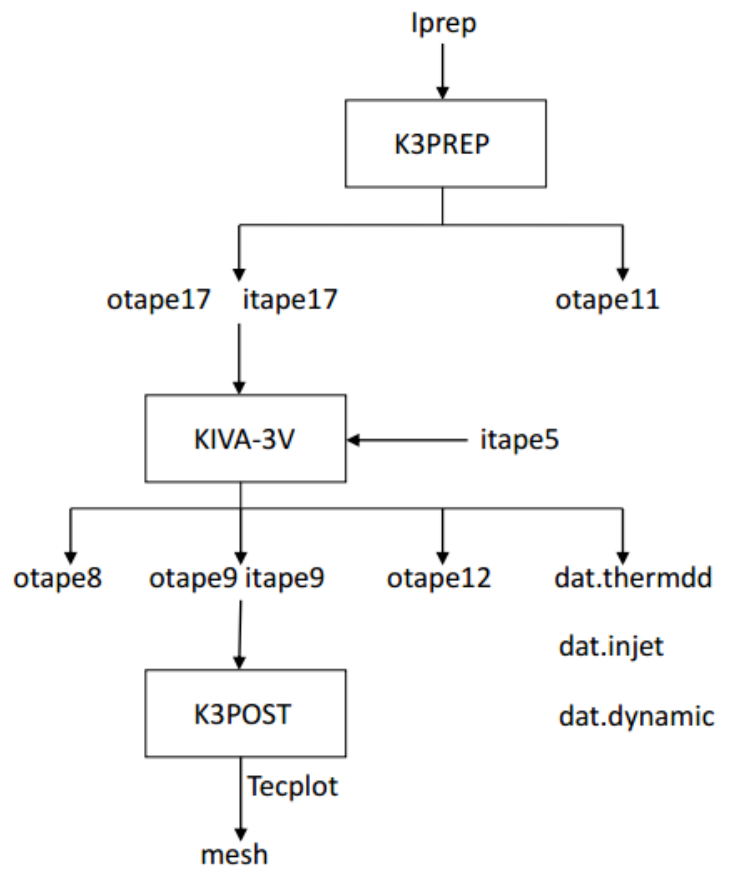

Fig. 1. The schematic of grid generation

Next, we will build a model of the combustion chamber of the Santana 2000 Age Superman gasoline engine. We need to design the iprep file and the itape 5 file. As the itape5 file involves swirl ratio, the ignition start time, the ignition duration and the top temperature of the cylinder, the piston surface temperature, the fuel injection quantity and the fuel injection mode, it is very complicated. Therefore we mainly introduce the process of designing the iprep file. The specific process of designing the iprep file is as follows:

\section{A. Simulation name and engine parameters}

The first line of the iprep file is defined by the name of the simulation, which gives the type of the engine and the code of the simulation. And the first line is not involved in the calculation. The engine parameters are defined by the second line to the fourth line in the iprep file. It includes the bore, the stroke and the squish. According to the Santana 2000 Age Superman gasoline engine, the parameters are as followed. Bore $=8.0 \mathrm{~cm}$; stroke $=8.64 \mathrm{~cm}$; squish $=0.15 \mathrm{~cm}$. The fifth line of the iprep file is the thsect which represents the geometry type of the simulation. If thsect $=0.5$, it represents two dimensional simulation. If thsect $=360^{\circ}$, it means the full cylinder mesh of three dimensional simulation. If thsect $=180^{\circ}$, it means half of the cylinder mesh.

\section{B. Defining the block}

The sixth line of the iprep file defines the number of geometric blocks within the engine cylinder. Simple shapes can be used to describe the geometrical features of the coordinate method. In this paper, we use three blocks. This method is simple and practical. Fig.2 is block of combustion zone. Block1 is the combustion chamber block. Block2 and Block3 are not combustion chamber blocks.

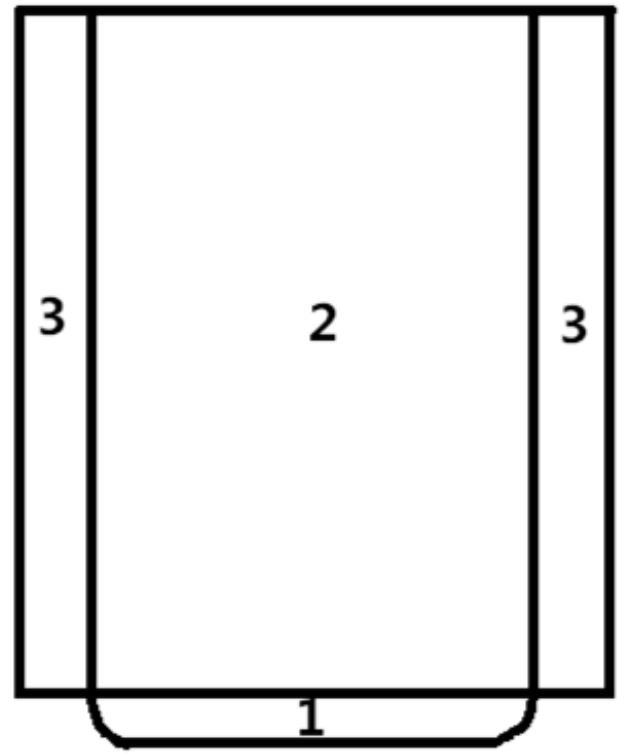

Fig. 2. Block of combustion zone

\section{Defining the combustion chamber block}

In this part we define the feature of the combustion chamber block and marks, the block of the 8 corner coordinates, the 6 face marks, the coordinate of combustion chamber' section plan and the 6 surface movement marks. The coordinate of combustion chamber' section plan is very 
important. As the combustion chamber is revolving body, we use two dimensional method to build the combustion chamber model. We used 39 points to describe the combustion chamber' section plan. Fig.3 is the section of the profile.



Fig. 3. The section of the profile

\section{RESULTS}

After designing the iprep file and the itape5 file, run K3PREP to get the itape17 file. Then run KIVA-3V to get the otape9 file. At last run K3POST to generate combustion chamber mesh data file. Use visual software to display the result. Then we can see the internal engine combustion chamber mesh (Fig.4). And it gives a new way to build up simulation grid for internal engine.

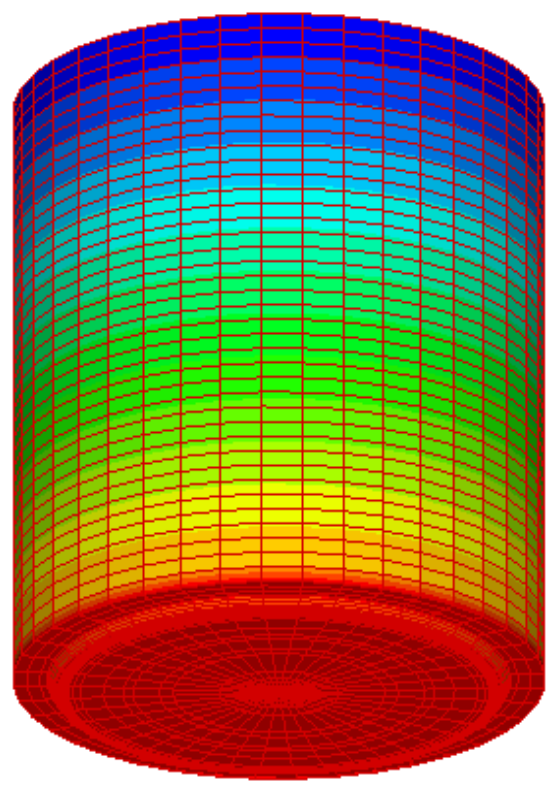

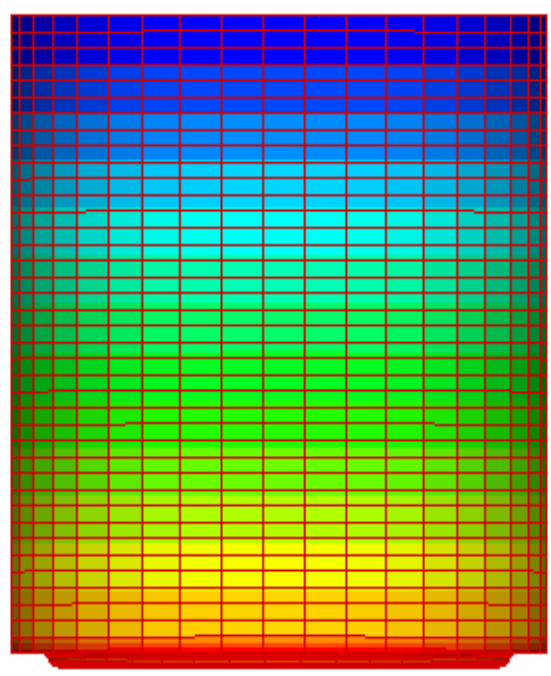

Fig. 4. Combustion chamber mesh

\section{CONCLUSIONS}

The flow field distribution of gasoline engine is complex, and the calculation results are very complicated. If only in the form of digital report output, it is difficult to grasp its law. Only by transforming these data into a wide variety of images can we effectively determine the correctness and the characteristics of the results. In this paper, the KIVA-3V program is used to construct the model of gasoline engine combustion chamber. After running KIVA-3V, we can get the combustion chamber mesh data file. Open the data file with graphics display software Tecplot. The three dimensional graph vividly shows the calculation results and provides a wealth of information about the flow field. And we can use the result to make the simulation of the combustion chamber. At last, we can get the new three dimensional grids of the intakeexhaust closing internal combustion engine. And it gives a new way to build up simulation grid for internal engine.

\section{Acknowledgment}

The study was sponsored by The Importation and Development of High-Caliber Talents Project of Beijing Municipal Institutions (CIT\&TCD20140311) and Beijing Natural Science Fund (SQKZ201510016004).

\section{References}

[1] Anthoy A. Amsden. KIVA-3V:A Block-Structured KIVA Program for Engines with Vertical or Canted Valves, LA-13313-MS,1997G.

[2] Jinwu Liu. Working process of internal combustion engine, ICFDCNmultidimensional modeling, 2010.11

[3] Amsden A A. A Gride Generator for the KIVA-3V Program with Valves [M]. New Mexico: Los Alamos National Laboratory, 1998,15-58I.

[4] Tecplot, Inc. Tecplot.360 user's manual, 2010 
[5] AmsdenAnthoy A,e al. The KIVA-II Computer Program for Transient Multidimensional Chemically Reactive Flows with Sprays[J]. SAE Transactions, 1987,96(7):373-384

[6] AmsdenAA.Rourke P J O,Butler T D.KIVA-II:A Computer Program for Chemically Reactive Flows with Sprays[M].New Mexico:Los Alamos National Laboratory,1989:6-45Y.

[7] Egel Urip, Ka Heng Liew, and S. L. Yang. Modeling IC Engine Conjugate Heat Transfer Using the KIVA Code [J]. Numerical Heat Transfer,2007,52:1-23.
[8] Liu Jinwu, Gong Jinke, Cai Longyu, et al. Multi-dimensional Simulation of Air/Fuel Premixing and Stratified Combustion in a Gasoline Direct Injection Engine with Combustion Chamber Bowl Offset[J]. SAE Paper,2006,75(9):75-82.

[9] D.J.Torres.KIVA-4 Manual (Theoretical Division, T-3 )[R], Los Alamos National Laboratory, NM87545,2007.

[10] Hiroyuki HIROYASU, Toshikazu KADOTA, Masataka ARAI, Development and Use of a Spray Combustion Modeling to Predict Diesel Engine Efficiency and Pollutant Emissions (Part 1 Combustion Modeling), Bulletin of the JSME,1983,26(214). 